\title{
Modified Transmission Line Protection Scheme in the Presence of SCC
}

\author{
Ehsan Mostaghimi Naeini*, Behrouz Vaseghi ${ }^{\dagger}$ and Mehdi Mahdavian*
}

\begin{abstract}
Distance relay identifies the type and location of fault by measuring the transmission line impedance. However any other factors that cause miss calculating the measured impedance, makes the relay detect the fault in incorrect location or do not detect the fault at all. One of the important factors which directly changes the measured impedance by the relay is series capacitive compensation (SCC). Another factor that changes the calculated impedance by distance relay is fault resistance. This paper provides a method based on the combination of distance and differential protection. At first, faulty transmission line is detected according to the current data of buses. After that the fault location is calculated using the proposed algorithm on the transmission line. This algorithm is based on active power calculation of the buses. Fault resistance is calculated from the active powers and its effect will be deducted from calculated impedance by the algorithm. This method measures the voltage across SCC by phasor measurement units (PMUs) and transmits them to the relay location via communication channels. The transmitted signals are utilized to modify the voltage signal which is measured by the relay. Different operating modes of SCC and as well as different faults such as phase-to-phase and phase-to-ground faults are examined by simulations.
\end{abstract}

Keywords: Series capacitive compensation (SCC), Flexible ac transmission system (FACTS) controllers, Trip boundaries, Phasor measurement units (PMUs)

\section{Introduction}

Distance relays are one of the most useful relays in transmission lines. However, several factors are causing relay may not properly function in the transmission line. Series capacitive compensation is one of the common devices to increase the exchange power in transmission lines. The second factor is fault resistance that cause increasing of the measured impedance by the distance relay and relay under-reach. There were many attempts to investigate these effects in various power system protections. Majority of the researches have surveyed these effects on impedance relays such as the distance relays of transmission lines and loss-of-excitation (LOE) relays of synchronous generators, which both operate based on the impedance measurements. The distance relay performance is analyzed in [1-11] in the presence of FACTS controllers. These studies include three major investigation categories; which deal with; a) shunt-FACTS such as static Var compensator (SVC) and static synchronous compensator (STATCOM) [1-4], b) series-FACTS such as SSSC and thyristor controlled series capacitor (TCSC) [5-7], and c) shunt-series-FACTS such as unified powerflow controller (UPFC) and generalized interline powerflow controller (GIPFC) effects [8-11]. The results of these articles expresses that the series and shunt-series-

$\dagger$ Corresponding Author: Department of Electrical Engineering, Abhar Branch, Islamic Azad University, Abhar, Iran. (vaseghi@abhariau.ac.ir)

* Department of Electrical Engineering, Naein Branch, Islamic Azad University, Naein, Iran. (\{mostaghimi_naeini, meh_mahdavian\}@ yahoo.com)

Received: November 18, 2015; Accepted: November 22, 2016
FACTS controllers have more negative effects on the distance relays operation than other devices. This is due to the fact that they increase the zero sequence component of the injected voltage during fault. Also, it is observed that the most severe effects occur under phase-to-ground fault, which usually lead to the relays under-reaching.

The LOE relay performance is studied in [12-15] in the presence of FACTS controllers. It is shown in $[12,13]$ that the presence of STATCOM and SVC causes delay in the LOE relay response. Also [14] shows that the GIPFC cause delay in the LOE relay response and a PMUs-based modified LOE relay has been presented. It is also shown in [15] that the presence of SCC and static synchronous series compensator (SSSC) causes the LOE relay to be underreached. Majority of recent studies use the PMUs to measure the voltage and current signals which are injected by the FACTS as these controllers are usually located in the middle of the transmission line and it is necessary to transmit the measured data to the relays location. This method is used in [10] to modify the distance relay operation in the presence of UPFC using a generalized regression neural network algorithm. In [14], the signals of PMUs which are located at both ends of the transmission line are transmitted to relay location to eliminate the negative effects of GIPFC on the LOE relay. Also [16-18] utilize PMUs to eliminate the series capacitive compensators effects on the distance relays. These studies use a relay which is not able to calculate the fault resistance $\left(R_{f}\right)$.

This paper represents that the presence of SCC in transmission line reduces the measured impedance by relay. In other words it causes relay over-reaching which disturbs 
the backup protection of transmission lines. Finally, a simple and feasible method is proposed to remove the detrimental effects of the SCC on the measured impedance of the distance relays. The proposed method is a combining of differential and distance protection. The data of buses containing voltage and current signals are sent to the relay location or system protection center (SPC). Then using obtained phasros, the effect of fault resistance and SCC is removed from the measured impedance. In this method, protection zones are not changed and backup protection is established similar to the distance protection. Since in this method, the calculated impedance is modified, so the fault location is identified precisely. The proposed method doesn't use intricate algorithms and its capability for various high resistance faults has been proved.

\section{Modelling of System with Distance Relayes}

The active power transmitted by transmission line is reversely proportional to the reactance of the line. Hence it's common, compensating the reactance to maximize the exchanged power in transmission line. With the recent advances in power systems, the SCC controllers have taken the place of the conventional compensators. These devices possess advantages such as controlling capabilities and quick response under critical conditions. The test power system (shown in Fig. 1) comprises three transmission lines which each one has $200 \mathrm{~km}$ length. The series compensator is placed at the middle of the line- 2 and distance relays (which each one has three protective zones) are located at the beginning of the lines. For instance, the zone- 1 of the relay $R_{A}$, comprises $80 \%$ of the transmission line-1; the zone- 2 comprises entire of line- 1 and $50 \%$ of the line-2; and the zone- 3 comprises whole of lines- 1 and 2 and also $20 \%$ of the line-3. The other relays are similar to $R_{A}$. Also, backup protection has been provided with applying delay to the operation of zones- 2 and 3 of the distance relays. The modelled distance relay can measure the fault resistance. Since high-resistance faults cause the relays under-reaching, different methods have been proposed to eliminate the under-reaching [19-23]. Some of them change the protective zones of relays so that the calculated impedance by relays falls into the right protective zones even under high-resistance faults conditions. This concept, so-called trip boundaries, is explained in the following sections

\section{Impact of SCC on Distance Protection}

The positive, zero and negative sequence networks of the power system from the sight of $R_{B}$ relay is shown in Fig. 2 . In this figure, SCC has a series impedance making the SCC functions as a variable or controllable voltage source while the current flows through this impedance. The positive-sequence voltage at $R_{B}$ relay location $\left(V_{l B}\right)$ can be expressed as:

$$
V_{1 B}=x Z_{1 L} I_{1 B}+R_{f} I_{1 f}+\Delta V_{1}+V_{1 f}
$$

The negative $\left(V_{2 B}\right)$ and zero $\left(V_{O B}\right)$ sequence voltages are extracted from Fig. 3 in the same way:

$$
V_{2 B}=x Z_{1 L} I_{2 B}+R_{f} I_{2 f}+\Delta V_{2}+V_{2 f}
$$

and

$$
V_{0 B}=x Z_{0 L} I_{0 B}+R_{f} I_{0 f}+\Delta V_{0}+V_{0 f}
$$

For a single-phase-to-ground fault, the following
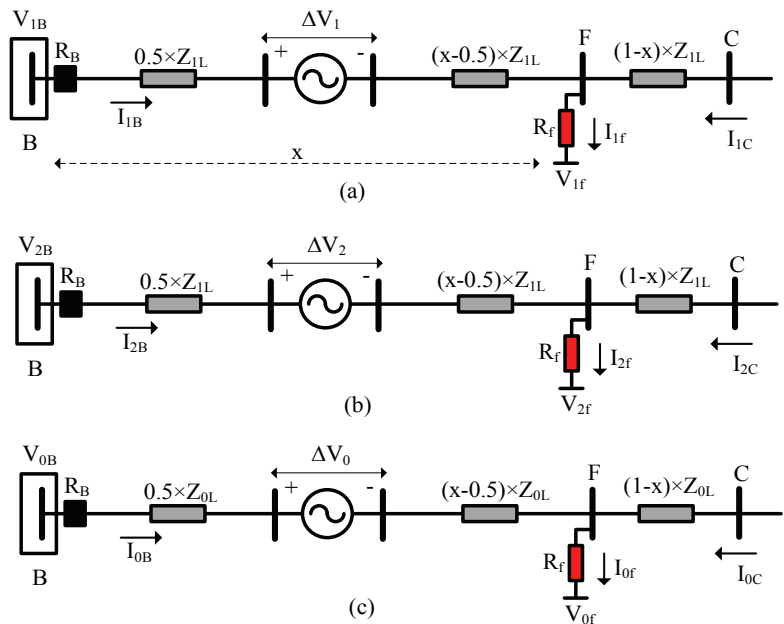

Fig. 2. Positive (a), negative (b) and zero-sequence (c) networks of the power system from the viewpoint of the $R_{B}$ relay for an A-G fault on line-2

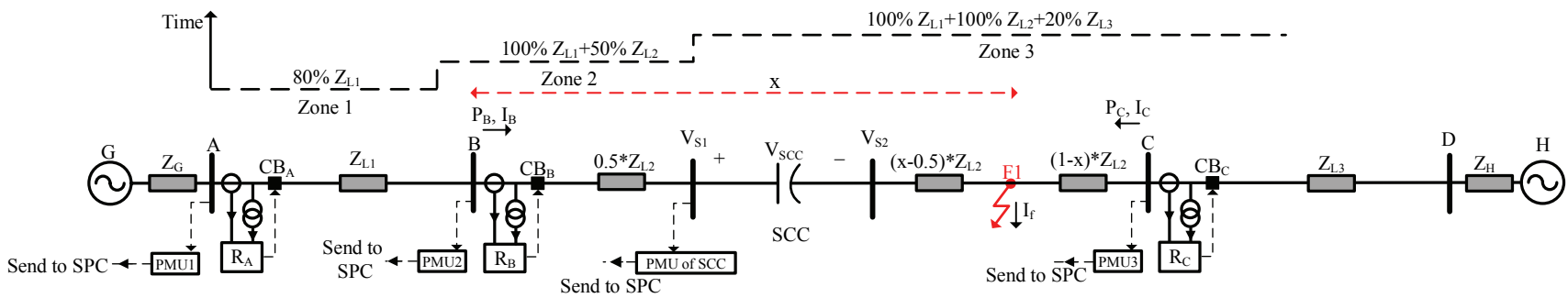

Fig. 1. Single-line diagram of multi-line system with the SCC 
equations are used:

$$
\begin{gathered}
I_{B}=I_{1 B}+I_{2 B}+I_{0 B} \\
I_{f}=I_{1 f}+I_{2 f}+I_{0 f} \\
\Delta V=\Delta V_{1}+\Delta V_{2}+\Delta V_{0}
\end{gathered}
$$

and

$$
V_{B}=V_{1 B}+V_{2 B}+V_{0 B}
$$

Replacing the voltages $V_{I B}, V_{2 B}$ and $V_{O B}$ into equation (7) and considering that $V_{l f}+V_{2 f}+V_{0 f}=0$ is valid for singlephase-to-ground fault, the following equation can be derived:

$$
\begin{aligned}
& V_{B}=V_{1 B}+V_{2 B}+V_{0 B}=x Z_{1 L} \underbrace{\left(I_{1 B}+I_{2 B}+I_{0 B}\right)}_{I_{B}} \\
& -x Z_{1 L} I_{0 B}+R_{f} \underbrace{\left(I_{1 f}+I_{2 f}+I_{0 f}\right)}_{I f}+x Z_{0 L} I_{0 B} \\
& +\underbrace{\left(\Delta V_{1}+\Delta V_{2}+\Delta V_{0}\right)}_{\Delta V}= \\
& x Z_{1 L} I_{B}+x I_{0 B}\left(Z_{0 L}-Z_{1 L}\right)+R_{f} I_{f}+\Delta V
\end{aligned}
$$

The purpose is acquiring the impedance of transmission line from the relay location until fault location $\left(x Z_{I L}\right)$. After simplifying the (8) the (9) is achieved.

$$
V_{B}=x Z_{1 L} \underbrace{\left(I_{B}+I_{0 B}\left(Z_{0 L}-Z_{1 L}\right) / Z_{1 L}\right)}_{I_{A-G}}+R_{f} I_{f}+\Delta V
$$

Calculated impedance by relay $\left(Z_{\text {Relay }}\right)$ can be derived as below:

$$
Z_{\text {Re lay }}=\frac{V_{B}}{I_{A-G}}=x Z_{1 L}+\underbrace{R_{f} \frac{I_{f}}{I_{A-G}}}_{\Delta Z_{R f}}+\underbrace{\frac{\Delta V}{I_{A-G}}}_{\Delta Z_{S C C}}
$$

According to (10), it can be observed that without series capacitor the terminal voltage of capacitor $(\Delta V)$ is equal to zero. When the fault resistance is zero the $\Delta Z_{R f}$ will be zero and consequently the relay operates properly and the measured impedance is equal to $x Z_{I L}$. With the presence of series capacitor and fault resistance, the measured impedance by relay is not equal to $x Z_{I L}$ anymore. Two terms $\Delta Z_{S C C}$ and $\Delta Z_{R f}$ are added to $x Z_{I L}$. So it is not possible to identify the fault location by means of an ordinary method and as a result the relay will operate incorrectly. The objective of this section was that to analyze the reason of miss operating the relay at the presence of capacitor.

For a phase-to-phase fault, one can write:

$$
V_{1 f}+a V_{2 f}=0
$$

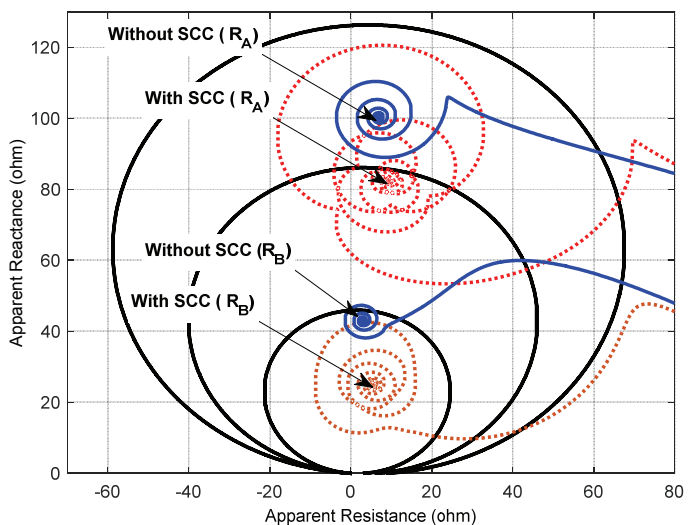

Fig. 3. Apparent impedance seen by conventional relays for an A-G fault at $150 \mathrm{~km}$ from the $R_{B}$

Where $a=-0.5+\mathrm{j} 0.866$. For $\mathrm{A}-\mathrm{B}$ fault, the apparent impedance measured by $R_{B}$ relay is:

$$
\begin{aligned}
& Z_{A-B}=\frac{V_{1 B}-a \cdot V_{2 B}}{I_{1 B}-a \cdot I_{2 B}}=\frac{V_{1 B}-a \cdot V_{2 B}}{I_{A-B}}= \\
& x Z_{1 L}+\underbrace{\frac{\Delta V_{1}-a \cdot \Delta V_{2}}{I_{A-B}}}_{\Delta Z_{A-B}}
\end{aligned}
$$

For a phase-to-phase fault, the impact of compensator on the apparent impedance is expressed by $\Delta Z_{A-B}$. Since the series compensator affects the calculated impedance via the voltage across of terminals $(\Delta V)$, thus by knowing this voltage and transmitting it to the relay location, it's possible to recognize and calculate these effects. In the next section, this method is explained by the results of simulations.

Results of simulation for single phase-to-ground fault, A-G, $150 \mathrm{~km}$ away from $R_{B}$ relay and $350 \mathrm{~km}$ away from $R_{A}$ relay (F1 fault) are depicted in Fig. 3. This fault is occurring at the zone- 2 of $R_{A}$ relay and zone- 1 of $R_{B}$ relay. The results in Fig. 3 show that the relays easily detect the fault in their correct zones when the SCC is not connected to the line-2. At presence of SCC the calculated impedance by the relays diminishes which causes both relays overreaching. This over-reaching of $R_{A}$ relay is very severe so that the fault falls into zone- 2 of the relay. The results provided in Fig. 3 belong to 50\% compensation operation modes of the SCC. Exclusive discussions about the SCC effects on distance relays performance are presented in many articles as well. Herein, the main goal of this paper which is proposing a method to eliminate the negative effects has been investigated.

\section{Modified Distance-Differential Protection Scheme}

Analytical analysis indicates that distance relay measuring 
the transmission line impedance can detect the type and location of the fault.

But as it can be seen, the presence of fault resistance and SCC changes the calculated impedance by the relay, which leads to relay mal-operation. Nowadays, utilizing PMUs and communication channels makes it feasible to use differential protection in transmission lines which does not have problems of the distance relay. Differential protection would not be affected by the fault resistance however, this type of protection can only discriminate the existence of the fault and it's not able to identify the fault location. The following method is combination of distance and differential protection methods which has their advantages simultaneously.

Nowadays, the PMUs are widely used to improve the performance of power system equipment like the relays and stabilizers. This method uses PMUs to measure the required information of different locations in the power system and sends them to the controlling center; then, by means of these data an adequate control signal is generated to boost system performance. Communication channels like optical fibers are utilized in this method to transmit the data [24]-[26]. Using current information of the buses and their inequality during the fault, fault condition is detected. Then, using voltage and current information of the buses, active power related to the buses $\mathrm{B}$ and $\mathrm{C}$ are calculated. The sum of this active power is lost in $x^{*} R_{L 2},(1-x)^{*} R_{L 2}$, and $R_{f}$ resistors (Fig. 4). We will have:

$$
\begin{aligned}
P_{B}+P_{C}= & x R_{L 2} \times I_{B}^{2}+(1-x) R_{L 2} \times I_{C}^{2} \\
& +R_{f} \times\left(I_{B}+I_{C}\right)^{2}
\end{aligned}
$$

In (13), $R_{f}$ is much larger than $x^{*} R_{L 2}$ and $(1-x)^{*} R_{L 2}$, therefore these two resistances can be ignored. As a result, the above equation can be simplified as follows:

$$
R_{f} \cong \frac{P_{B}+P_{C}}{\left(I_{f}\right)^{2}}
$$

Now in (14), $P_{B}$ and $P_{C}$ are calculated and current data are available and then the only unknown $\left(R_{f}\right)$ will be calculated. After calculating $R_{f}$, its effect $\left(\Delta Z_{R f}\right)$ from calculated impedance by (10) is eliminated. Therefore, $R_{f}$ effect is eliminated and calculated impedance by the relay is corrected and using that, fault location or $x$ is obtained. For simplification, this method is brought in the Fig. 4. Voltage and current data in both ends of the transmission line are transmitted to the system protection center (SPC). Firstly, currents in both ends of the transmission line are compared and if their differences is bigger than $I_{\text {set }}$ (setting current), it shows that fault exists. In the second step, using current and voltage data, active power is calculated in both ends of the transmission line. Then, using (14), $R_{f}$ is calculated and using (10), $\Delta Z_{R f}$ will be calculated. As it was seen in theoretical analyses, the presence of SCC changes

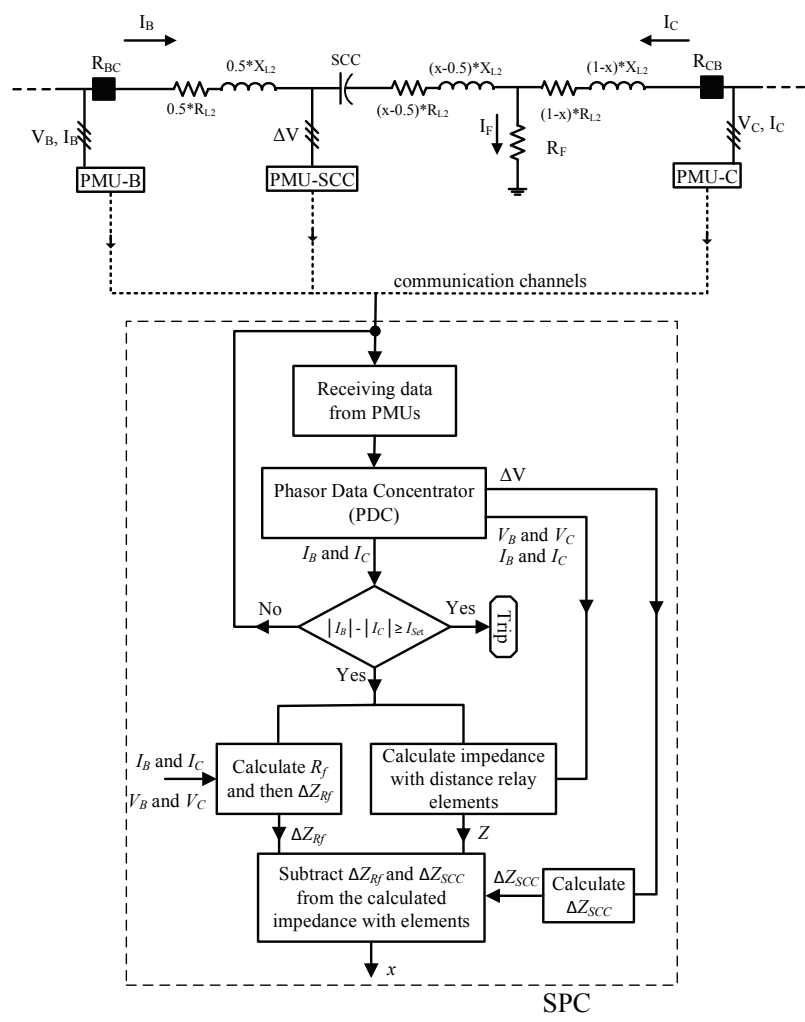

Fig. 4. Modified differential-distance protection scheme

the calculated impedance by the relays because the $\Delta V$. To eliminate this term, the voltage across the compensator is measured as shown in Fig. 1 and is sent to SPC and using (10), $\Delta Z_{S C C}$ is calculated. After detecting the fault condition, using voltage and current in both ends of the transmission line, line impedance (same as distance relay) is calculated. Each distance relay has six elements to identify different faults. For example in (10), equation of A-G element is presented. In the last step, obtained $\Delta Z_{R f}$ and $\Delta Z_{S C C}$ are deducted from the calculated impedance. Therefore, from modified impedance, $x$ or fault location is obtained. In this algorithm at first, fault is immediately detected from current information and after that the fault location is estimated according to receiving data from PMU and using proposed method. In other words, the calculation process of fault location identification is separated from fault detection and is performed after that. So it has no delaying effect on relay performance. The simulation results for A-G and A-B faults at presence of SCC are depicted in Figs. 5 (a) and (b), respectively. The faults are $110 \mathrm{~km}$ from the relay $R_{B}$ and the presented results belong to $50 \%$ compensation. Regarding the results, the presence of SCC decreases the relay measured impedance which causes the relay over-reaching. Furthermore, using the voltage across SCC eliminates its effect on the measured impedance by relay. Results of simulations for different compensations and different fault locations are provided in Table 1. The faults location is deliberately selected so that the SCC falls into the desired fault loops. The distances in the Table 1 
Table 1. Performance of conventional (Con) and modified (Mod) distance relay with

\begin{tabular}{|c|c|c|c|c|c|c|c|c|c|c|}
\hline & Fault Distance & \multicolumn{2}{|c|}{$310 \mathrm{~km}$} & \multicolumn{2}{|c|}{$350 \mathrm{~km}$} & \multicolumn{2}{|c|}{$400 \mathrm{~km}$} & \multicolumn{2}{|c|}{$450 \mathrm{~km}$} & \\
\hline & Method & Con & Mod & Con & Mod & Con & Mod & Con & Mod & \\
\hline \multirow{3}{*}{$\begin{array}{l}\text { A-G } \\
\text { Fault }\end{array}$} & $20 \%$ Com & $7.25 \Omega$ & $0.004 \Omega$ & $7.24 \Omega$ & $0.010 \Omega$ & $7.28 \Omega$ & $0.027 \Omega$ & $7.48 \Omega$ & $0.040 \Omega$ & \multirow{6}{*}{ 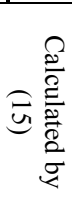 } \\
\hline & $50 \%$ Com & $18.3 \Omega$ & $0.009 \Omega$ & $18.3 \Omega$ & $0.013 \Omega$ & $18.5 \Omega$ & $0.026 \Omega$ & $18.9 \Omega$ & $0.038 \Omega$ & \\
\hline & $70 \%$ Com & $25.5 \Omega$ & $0.012 \Omega$ & $25.9 \Omega$ & $0.020 \Omega$ & $26.3 \Omega$ & $0.032 \Omega$ & $26.8 \Omega$ & $0.052 \Omega$ & \\
\hline \multirow{3}{*}{$\begin{array}{l}\text { A-B } \\
\text { Fault }\end{array}$} & $20 \%$ Com & $11.4 \Omega$ & $0.021 \Omega$ & $11.5 \Omega$ & $0.027 \Omega$ & $11.4 \Omega$ & $0.048 \Omega$ & $11.5 \Omega$ & $0.080 \Omega$ & \\
\hline & $50 \%$ Com & $28.7 \Omega$ & $0.043 \Omega$ & $28.6 \Omega$ & $0.017 \Omega$ & $28.6 \Omega$ & $0.066 \Omega$ & $28.7 \Omega$ & $0.033 \Omega$ & \\
\hline & $70 \%$ Com & $40.2 \Omega$ & $0.005 \Omega$ & $40.2 \Omega$ & $0.027 \Omega$ & $40.1 \Omega$ & $0.048 \Omega$ & $40.2 \Omega$ & $0.091 \Omega$ & \\
\hline
\end{tabular}

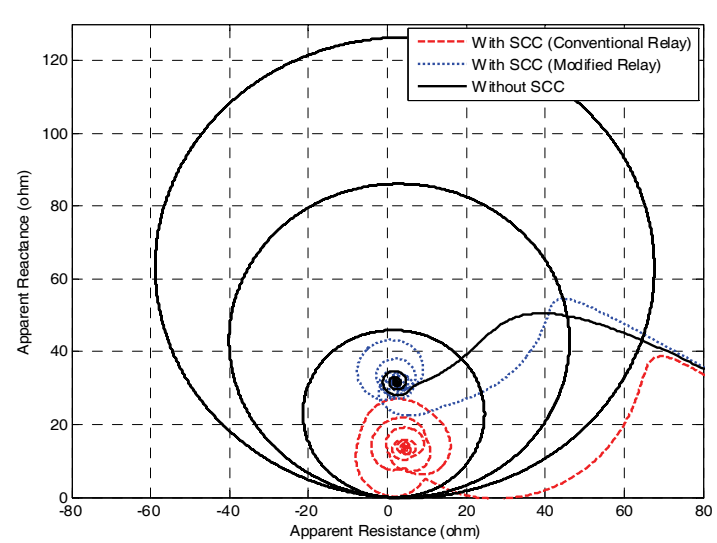

(a)

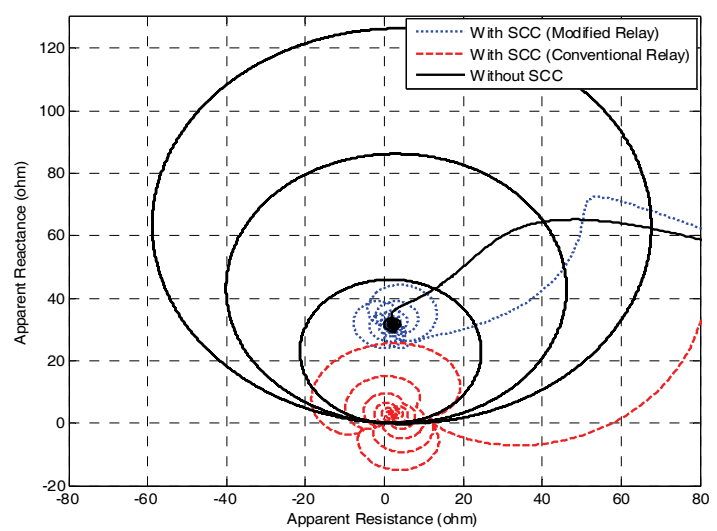

(b)

Fig. 5. Calculated apparent impedance by $R_{B}$ relay for an $\mathrm{A}-\mathrm{G}$ (a) and A-B (b) fault at $150 \mathrm{~km}$ from the $R_{B}$

show the place of faults with respect to $R_{A}$ relay. The following equation is used to compute the data presented in the Table 1 .

$$
\text { Error }=\left|Z_{W O}-Z_{W}\right|
$$

Where $Z_{W O}$ and $Z_{W}$ are the relay measured impedance without and with the SCC connected to the line, respectively. Regarding Table 1, for all the compensation percentages, the effect of SCC under phase-to-phase faults is more critical than phase-to-ground faults. For instance, the impedance differences due to SCC effect for A-G and A-B faults in $310 \mathrm{~km}$ and for $70 \%$ compensation are 25.5 and $40.2 \Omega$, respectively. For both cases, the effect of SCC is increased when the compensation percentage increases.

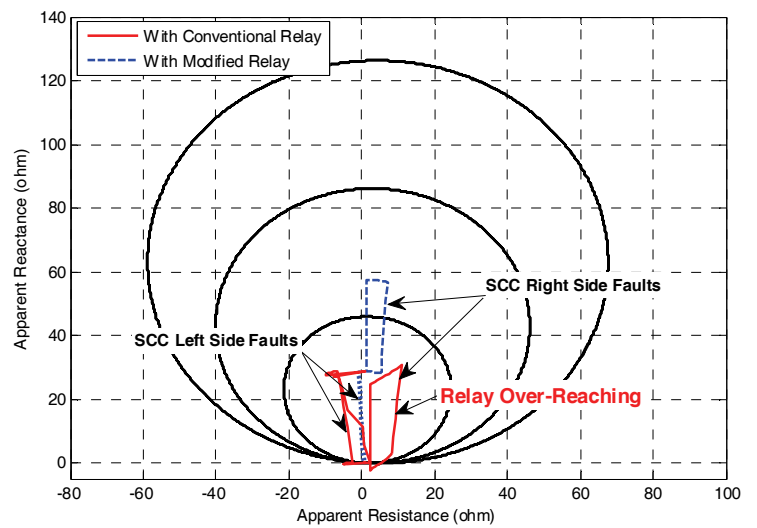

Fig. 6. Trip boundaries calculated by the $A-G$ element of $R_{B}$ in the presence of SCC (70\% compensation)

Finally, comparing the conventional relay with the modified relay, it is concluded that the modified method decreases the impedance difference into less than $0.1 \Omega$ for all different types of faults and under all the operating modes. For example, the maximum over-reaching for $70 \%$ compensation belongs to A-B fault occurring in $310 \mathrm{~km}$ away from the relay $R_{A}$ with an amount of $40.2 \Omega$ whereas the new modified method eliminates it by decreasing it into $0.005 \Omega$. In other words, the modified method eliminates the SCC negative effects under any operating modes of the system. The results presented above belong to zero fault resistance. Herein, the new modified method's feasibility and capability in the presence of the SCC under highresistance faults are investigated. Application of "trip boundaries" is a reliable method for evaluating the fault resistance effect on the measured impedance by the relay. The fault location and resistance are considered as two notable parameters in this method. At the first step, the fault is located at the beginning of transmission line and the fault resistance $\left(R_{f}\right)$ is increased from zero to $300 \Omega$. At second step, the fault resistance is fixed to $300 \Omega$ and its location is varying from the beginning to the end of the transmission line. At the third step, the fault is located at the end of the line and the fault resistance is changing from $300 \Omega$ to $0 \Omega$. At the final step, the fault resistance is fixed to zero and the location is varying from the end of the transmission line to its beginning. The $R_{f}$ and fault location increments are considered to be $30 \Omega$ and $20 \mathrm{~km}$, respectively. The trip boundaries for A-G fault in the presence of $70 \% \mathrm{SCC}$ are demonstrated in Fig. 6. It is 
comprehended that the presence of SCC divides the trip boundaries into two parts: part-1 for the faults which occur at the left side of the compensator and part-2 for the faults occurring at the right side of the compensator. For the part2 , the compensator is fallen in the fault loop. When the fault occurs at the left hand side of the compensator, the compensator is not fallen in fault loop and it affects the measured impedance provided that its resistance is not zero. Generally without SCC the faults located at the end of line2 and after $160 \mathrm{~km}$ should be fallen in zone- 2 of relay but according to the figure it's crystal clear that the presence of SCC caused relay overreaching and all faults have been fallen in its zone-1. On the other hand, using the novel method has solved this problem and all faults located at the end of line- 2 and after $160 \mathrm{~km}$ are truly detected and identified in zone-2. As it is demonstrated in this figure, the new method improves the relay sensitivity and accuracy under all fault types and operating modes. As it is observed in this figure, for all operating modes, the calculated impedance by the relay in the new algorithm falls in the right protective zones, while, in the conventional algorithm, there are conditions that the calculated impedance does not fall in the true zones (over-reaching) which means the system protection does not operate appropriately at those points.

\section{IEEE 14-Bus Power System}

One of the major objectives of this paper is to prove that the presence of SCC disturbs the backup protection of adjacent lines. From one side, distance relays have three operational zones. So, three consecutive lines have been used to clarify all three zones, as indicated in the Fig. 1. On the other hand since the transmission lines used in power

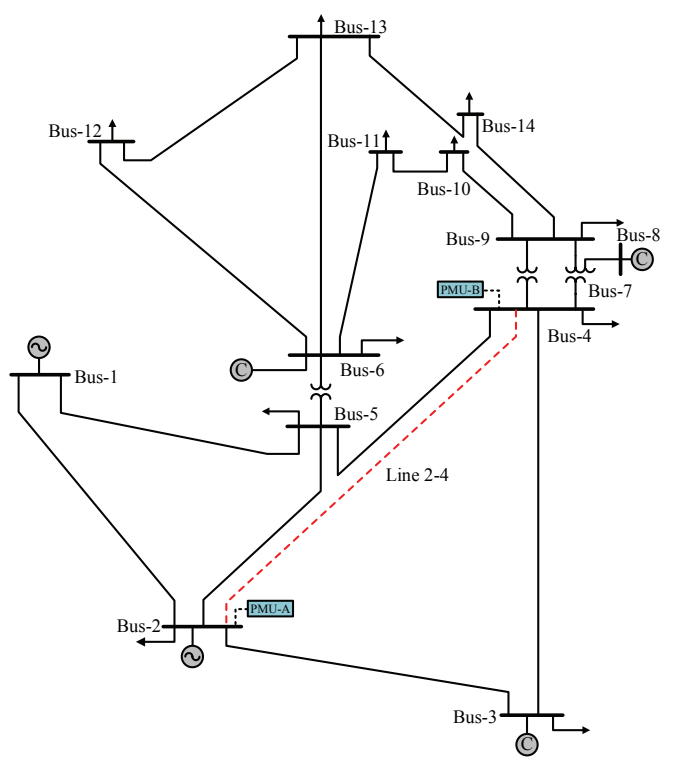

Fig. 7. Single-line diagram of IEEE 14-bus system systems are more complicated than in Fig. 1, the proposed method is examined for an IEEE 14-bus standard system which is depicted in Fig. 7.

A transmission line from bus-2 to bus-4 (line 2-4) has been considered which has an adjacent line and more complexity. Fig. 8 (a) illustrates the results of an A-G fault occurred in line 2-4 and $150 \mathrm{~km}$ away from bus-2 with assuming $R_{f}=0 \Omega$ and $50 \%$ compensation. As it can be observed, without SCC the relay has detected the fault in its zone-1. The presence of SCC reduces the impedance which leads to miss locating the fault by relay where the relay has detected the fault at $98 \mathrm{~km}$. However, using the proposed method the relay has discriminated the fault truly and the calculated impedance by relay is equal for both cases (with SCC and without SCC). The results of the same fault assuming $R_{f}=100 \Omega$ are presented in Fig. 8 (b). The results indicate that fault resistance has significantly changed the measured impedance by relay. The proposed method has modified the change in impedance so that the calculated impedance by the relay is equal in both cases $\left(R_{f}=0\right.$ and $100 \Omega$ ). In other words the presented method has eliminated the impact of fault resistance as well as the

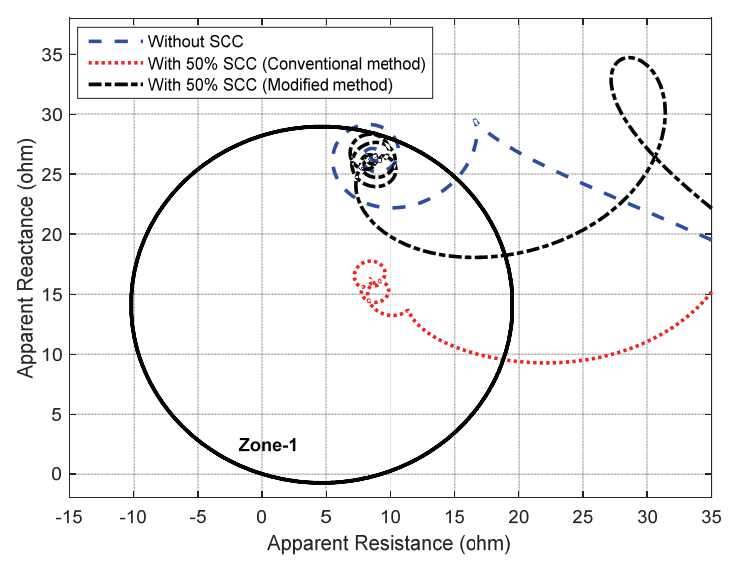

(a)

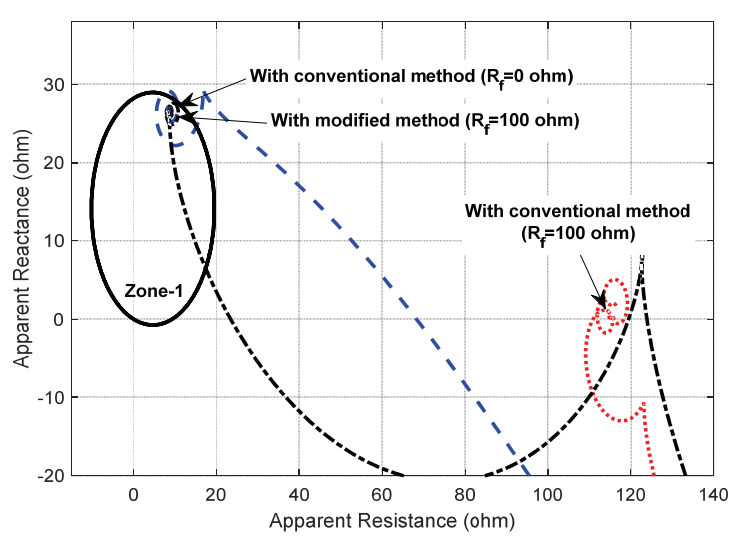

(b)

Fig. 8. Calculated apparent impedance by relay for an $A-G$ fault in line 2-4 and at $150 \mathrm{~km}$ from the bus- $2, R_{f}=0$ $\Omega$ (a) and $R_{f}=100 \Omega$ (b) 
capacitor effect on measured impedance by the relay simultaneously.

\section{Conclusion}

This paper investigates the effects of SCC, on the impedance measured by distance relays. The theoretical and simulation results indicated that the presence of SCC substantially affect the relays performance. The SCC always causes the relay to be over-reaching where it is more critical in case of phase-to-phase faults. It was observed that under different percentages of series compensation the distance relay operation is changing due to the SCC which disturbs the backup protection of relay. This paper provides a method that the voltage and current data of buses are sent to the SPC and faulty transmission line is detected according to the currents at the ends of lines (such as differential relay). Then with calculating the active power in buses, the fault resistance is obtained and its effect is deducted from calculated impedance in the algorithm. Also in this method, the voltage across the SCC is measured and transmitted to the SPC through communication channels for eliminating the effects of the SCC. Finally, the presented method has infrastructure of differential protection with difference that it can detect fault location.

\section{References}

[1] F. A. Albasri, T. S. Sidhu, and R. K. Varma, "Performance comparison of distance protection schemes for shunt-FACTS compensated transmission lines," IEEE Trans. Power Del., vol. 22, no. 4, pp. 21162125, Oct. 2007.

[2] M. Khederzadeh, and A. Ghorbani, "STATCOM modeling impacts on performance evaluation of distance protection of transmission lines," European Transaction on Electrical Power., vol. 21, no. 8, pp. 2063-2079, Nov. 2011.

[3] T. S. Sidhu, R. K. Varma, P. K. Gangadharan, F. A. Albasri, and G. R. Ortiz, "Performance of distance relays on shunt-FACTS compensated transmission lines," IEEE Trans. Power Del., vol. 20, no. 3, pp. 1837-1845, Jul. 2005.

[4] A. Ghorbani, B. Mozafari, and M. Khederzadeh, "Impact of SVC on the protection of transmission lines," International Journal of Electrical Power and Energy Systems., vol. 42, no. 1, pp. 702-709, Nov. 2012.

[5] S. R. Samantaray, "A data-mining model for protection of FACTS-based transmission line," IEEE Trans. Power Del., vol. 28, no. 2, pp. 612-618, Apr. 2013.

[6] M. Khederzadeh, and T. S. Sidhu, "Impact of TCSC on the protection of transmission lines," IEEE Trans. Power Del., vol. 21, no. 1, pp. 80-87, Jan. 2006.

[7] A. Ghorbani, B. Mozafari, and A. M. Ranjbar, "Digital distance protection of transmission lines in the presence of SSSC," International Journal of Electrical Power and Energy Systems., vol. 43, no. 1, pp. 712-719, Dec. 2012.

[8] R. Dubey, S.R. Samantaray, and B. K. Panigrahi, "Simultaneous impact of unified power flow controller and off-shore wind penetration on distance relay characteristics," IET Gener. Transm. Distrib., vol. 8, no. 11, pp. 1869-1880, Nov. 2014.

[9] M. K. Jena, S. R. Samantaray, and L. Tripathy, "Decision tree-induced fuzzy rule-based differential relaying for transmission line including unified power flow controller and wind-farms," IET Gener. Transm. Distrib., vol. 8, no. 12, pp. 2144-2152, Dec. 2014.

[10] K. Seethalekshmi, S. N.Singh, and S. C. Srivastava, "Synchrophasor assisted adaptive reach setting of distance relays in presence of UPFC," IEEE Systems Journal., vol. 5, no. 3, pp. 396-405, Sep. 2011.

[11] M. Khederzadeh and A. Ghorbani, "Impact of VSCbased multiline FACTS controllers on distance protection of transmission lines," IEEE Trans. Power Del., vol. 27, no. 1, pp. 32-39, Jan. 2012.

[12] M. Elsamahy, S. O. Faried, and T. Sidhu, "Impact of midpoint STATCOM on generator loss of excitation protection," IEEE Trans. Power Del., vol. 29, no. 2, pp. 724-732, Apr. 2014.

[13] A. Ghorbani, B. Mozafari, S. Soleymani, and A. M. Ranjbar, "Operation of synchronous generator LOE protection in the presence of shunt-FACTS," Electric Power Systems Research., vol. 119, pp. 178-186, Feb. 2015.

[14] A. Ghorbani, S. Soleymani, and B. Mozafari, "A PMU-based LOE protection of synchronous generator in the presence of GIPFC," IEEE Trans. Power Del., vol. 31, no. 2, pp. 551-558, Apr. 2016.

[15] A. Ghorbani, H. M. Lima, A. Azadru, and B. Mozafari, "Impact of fixed series capacitors and SSSC on the LOE protection of synchronous generator," J. Electr. Eng. Technol., vol. 10, no. 4, pp. 1453-1459, 2015.

[16] S. Sarangi, and A. K. Pradhan, "Synchronised databased adaptive backup protection for series compensated line," IET Gener. Transm. Distrib., vol. 8, no. 12, pp. 1979-1986, Dec. 2014.

[17] S. M. Hashemi, M. Tarafdar Hagh, and H. Seyedi, “A novel backup distance protection scheme for seriescompensated transmission lines," IEEE Trans. Power Del., vol. 29, no. 2, pp. 699-707, Apr. 2014.

[18] S. Sarangi, and A. K. Pradhan, "Steady state error estimation in distance relay for single phase to ground fault in series compensated parallel transmission lines," IET Gener. Transm. Distrib., vol. 8, no. 7, pp. 
1318-1337, Jan. 2014.

[19] A. D. Filomena, R. H. Salim, M. Resener, and A. S. Bretas, "Ground distance relaying with fault-resistance compensation for unbalanced systems," IEEE Trans. Power Del., vol. 23, no. 3, pp. 1319-1326, Jul. 2008.

[20] V. H. Makawana, and B. R. Bhalja, "A new digital distance relaying scheme for compensation of highresistance faults on transmission line," IEEE Trans. Power Del., vol. 27, no. 4, pp. 2133-2140, Oct. 2012.

[21] Z. Y. Xu, S. J. Jiang, Q. X. Yang, and T. S. Bi, "Ground distance relaying algorithm for high resistance fault," IET Gener. Transm. Distrib., vol. 4, no. 1, pp. 27-35, Jan. 2010.

[22] Q. K. Liu, S. F. Huang, H. Z. Liu, and W. S. Liu, "Adaptive impedance relay with composite polarizing voltage against fault resistance," IEEE Trans. Power Del., vol. 23, no. 2, pp. 586-592, Apr. 2008.

[23] M. M. Eissa, "Ground distance relay compensation based on fault resistance calculation," IEEE Trans. Power Del., vol. 21, no. 4, pp. 1830-1835, Oct. 2006.

[24] L. Chang, G. Chen, W. Gao, F. Zhang, and G. Li, "Adaptive time delay compensator (ATDC) design for wide-area power system stabilizer," IEEE Trans. Smart Grid., vol. 5, no. 5, pp. 2957-2966, Nov. 2014.

[25] J. D. L. Ree, V. Centeno, J. S. Thorp, and A. G. Phadke, "Synchronized phasor measurement applications in power systems," IEEE Trans. Smart Grid., vol. 1, no. 1, pp. 20-27, Jun. 2010.

[26] IEEE Standard for Synchrophasor Measurements for Power Systems, IEEE Std. C37.118-2005.

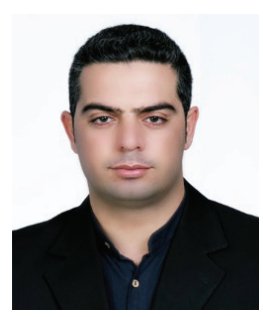

Ehsan Mostaghimi Naeini Was born in Naein, Esfahan, Iran, in 1980. Ehsan attended 4 years in high school and received his Diploma from Chamran high school in 1999. In 2008, he joined the Department of Electrical Engineering of IRISL group as a Engineer Officer. Since April 2010, he has been a full member of the Department of Electrical Engineering as Chief Electronic officer in large Shipping Company in Iran (IRISL) His current research interests include power electronics, electrical machines and drives.

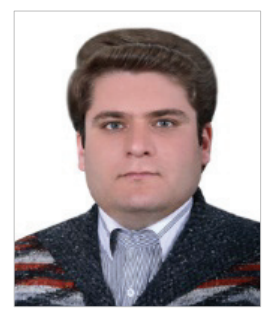

Behrouz Vaseghi Received the B.E. and M.E. degrees in electrical engineering from Islamic Azad University, NajafAbad branch, Esfahan, Iran in 2004 and 2008, respectively. currently $\mathrm{He}$ is a Ph.D. student in the communication and information systems in the School of Telecommunications Engineering, Islamic Azad University, Science and Research branch, Tehran, Iran. he is a Lecturer in the Department of Engineering, Islamic Azad University, Abhar Branch, Zanjan, Iran. His research interests include security and privacy for wireless networks, pattern recognition, image and signal processing and etc.

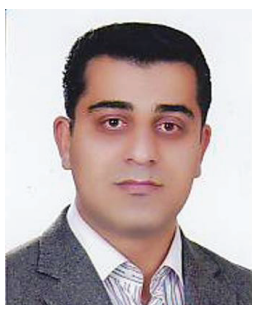

Mehdi Mahdavian Was born in Esfahan, Iran, in 1979. Mehdi attended 4 years in high school and received his Diploma from Alborz high school in 1997. He received the B.Sc. degree in electrical engineering from Kashan University, Kashan, Iran, in 2002, and the M.Sc. degrees in electrical engineering from Islamic Azad University (IAU), Najafabad Branch, Esfahan, Iran, in 200, respectively. Now, he is a $\mathrm{Ph} . \mathrm{D}$. candidate in electrical engineering from the King Mongkut's University of Technology Thonburi (KMUTT), Bangkok, Thailand. In 2002, he joined the Department of Electrical Engineering of IAU as a Lecturer. Since September 2007, he has been a full member of the Department of Electrical Engineering, IAU, Naein Branch. His current research interests include power electronics, electrical machines and drives, smart grids, flexible ac transmission systems, power system optimization, and renewable energies. 